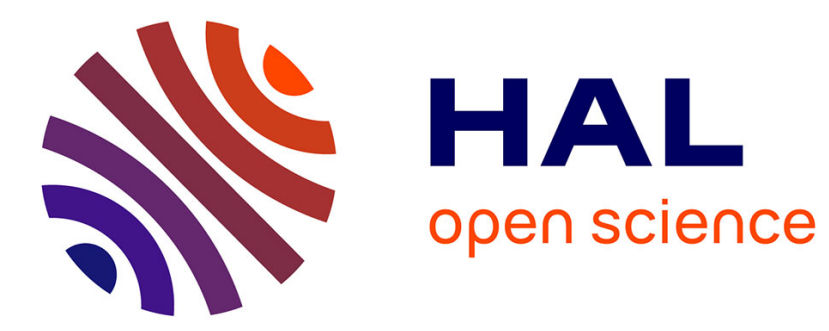

\title{
Investigating the sources of synoptic variability in atmospheric CO2 measurements over the Northern Hemisphere continents: a regional model study
} C. Geels, S. Doney, R. Dargaville, J. Brandt, J. Christensen

\section{- To cite this version:}

C. Geels, S. Doney, R. Dargaville, J. Brandt, J. Christensen. Investigating the sources of synoptic variability in atmospheric CO2 measurements over the Northern Hemisphere continents: a regional model study. Tellus B - Chemical and Physical Meteorology, 2004, 56 (1), pp.35-50. 10.1111/j.16000889.2004.00084.x . hal-03130358

\section{HAL Id: hal-03130358 \\ https://hal.science/hal-03130358}

Submitted on 21 Jun 2021

HAL is a multi-disciplinary open access archive for the deposit and dissemination of scientific research documents, whether they are published or not. The documents may come from teaching and research institutions in France or abroad, or from public or private research centers.
L'archive ouverte pluridisciplinaire HAL, est destinée au dépôt et à la diffusion de documents scientifiques de niveau recherche, publiés ou non, émanant des établissements d'enseignement et de recherche français ou étrangers, des laboratoires publics ou privés. 


\title{
Investigating the sources of synoptic variability in atmospheric $\mathrm{CO}_{2}$ measurements over the Northern Hemisphere continents: a regional model study
}

\author{
C. Geels, S. C. Doney, R. Dargaville, J. Brandt \& J. H. Christensen
}

To cite this article: C. Geels, S. C. Doney, R. Dargaville, J. Brandt \& J. H. Christensen (2004) Investigating the sources of synoptic variability in atmospheric $\mathrm{CO}_{2}$ measurements over the Northern Hemisphere continents: a regional model study, Tellus B: Chemical and Physical Meteorology, 56:1, 35-50, DOI: 10.3402/tellusb.v56i1.16399

To link to this article: https://doi.org/10.3402/tellusb.v56i1.16399

$$
\begin{aligned}
& \text { (c) } 2004 \text { The Author(s). Published by Taylor \& } \\
& \text { Francis. }
\end{aligned}
$$

\section{曲 Published online: 18 Jan 2017.}

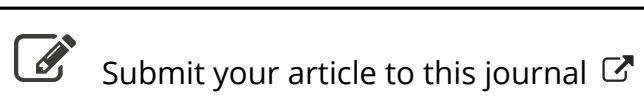

\footnotetext{
Џ Article views: 104
}

Q View related articles $\square$

\footnotetext{
Citing articles: 4 View citing articles 5
} 


\title{
Investigating the sources of synoptic variability
} in atmospheric $\mathrm{CO}_{2}$ measurements over the Northern Hemisphere continents: a regional model study

\author{
ByC. GEELS ${ }^{1 *}$, S. C. DONEY ${ }^{2}$, R. DARGAVILLE ${ }^{3}$, J. BRANDT ${ }^{1}$ and J. H. CHRISTENSEN ${ }^{1}$, \\ ${ }^{1}$ National Environmental Research Institute, Department of Atmospheric Environment, DK-4000 Roskilde, Denmark; \\ ${ }^{2}$ Woods Hole Oceanographic Institution, Woods Hole, MA 02543, USA $;{ }^{3}$ Laboratoire des Sciences du Climat et de \\ l'Environnement, 91191 Gif sur Yvette, France
}

(Manuscript received 20 December 2001; in final form 7 July 2003)

\begin{abstract}
Continuous measurements of atmospheric $\mathrm{CO}_{2}$ over the continents are potentially powerful tools for understanding regional carbon budgets, but our limited understanding of the processes driving the high-frequency variability in these measurements makes interpretation difficult. In this paper we examine the synoptic variability ( $\sim$ days) of surface $\mathrm{CO}_{2}$ concentrations in four continental records from Europe and North America. Three source functions corresponding to the ocean, land biosphere and anthropogenic sources and sinks for $\mathrm{CO}_{2}$ have been implemented in a regional atmospheric transport model. In previous carbon studies, monthly biospheric fluxes have typically been used, but here high spatiotemporal (daily, $1^{\circ} \times 1^{\circ}$ ) resolution biospheric fluxes are obtained from the NCAR Land Surface Model (LSM). A high-pass filter is used to remove atmospheric variability on time scales longer than 2 months, and the resulting simulated concentration fields replicates reasonably well the magnitude and seasonality of the synoptic variability across the four observation sites. The phasing of many of the individual events are also captured, indicating that the physical and biogeochemical dynamics driving the model variability likely resemble those in nature.

The observations and model results show pronounced summer maxima in the synoptic $\mathrm{CO}_{2}$ concentration variability at the two stations located in North America, while a slightly different seasonality with high variability throughout fall and winter is observed at the European sites. The mechanisms driving these patterns are studied and discussed based on correlations between the concentration anomalies and the driving atmospheric physical variables and surfaces fluxes in the simulations. During the summer, the synoptic variability over the continents has a significant contribution from variations in regional net primary production, which in turn is modulated by regional, synoptic temperature variability. In winter the synoptic variability is partitioned about equally between biospheric and anthropogenic $\mathrm{CO}_{2}$ and is mainly driven by local vertical mixing and synoptic variations in atmospheric circulation working on the large-scale atmospheric gradient. This study highlights the importance for future modeling work of improved high temporal resolution (at least daily) surface biosphere, oceanic and anthropogenic flux estimates as well as high vertical and horizontal spatiotemporal resolution of the driving meteorology.
\end{abstract}

\section{Introduction}

Over the last $10-15$ yr the global atmospheric $\mathrm{CO}_{2}$ monitoring network has grown substantially and today includes several stations collecting continuous observations over the continents. Continuous continental records of $\mathrm{CO}_{2}$ show variability over a range of scales, from interannual and seasonal, to synoptic and diurnal (e.g. Haszpra, 1995). In this paper we concentrate on the synoptic scales (order of days), but will also comment briefly

\footnotetext{
*Corresponding author.

e-mail: cag@dmu.dk
}

on the role of the diurnal variability. The higher frequency variability is often regarded as noise, but these variations contain information on the spatial and temporal variations of regional sources/sinks for atmospheric $\mathrm{CO}_{2}$ and mesoscale atmospheric transport. In a theoretical study, Law et al. (2002) demonstrated the benefits of using continuous data in an atmospheric inversion, providing a tighter constraint on longer-term flux estimates, but also highlighted the need for careful use of the concentration data.

The majority of global models used in both forward and inverse $\mathrm{CO}_{2}$ studies have coarse spatial and temporal resolution and use smooth, monthly average surface $\mathrm{CO}_{2}$ fluxes 
(Erickson et al., 1996; Bousquet et al., 2000; Dargaville et al., 2000, and others). For example, the suite of global threedimensional models included in the TransCom project typically have horizontal resolutions in the range of a few degrees up to $10^{\circ}$ (Law et al., 1996; Gurney et al., 2002). They cannot, therefore, take full advantage of the high-frequency information being collected in the continental interiors. For the inversions, this results in poorly constrained flux estimates over the continents. Gloor et al. (2000) suggest that more stations over the continents would improve the inversion results, but to take advantage of such measurements requires finer resolution models, better representation of the surface fluxes and variability, and an understanding of the processes driving the high-frequency variability.

Continental surface $\mathrm{CO}_{2}$ concentration records reflect the interaction of a range of physical and biogeochemical factors. While typically located away from local point sources, time series will be influenced by variability in regional surface $\mathrm{CO}_{2}$ fluxes from both anthropogenic sources and the land biosphere. The biospheric fluxes in turn vary in response to local and regional weather patterns (e.g. temperature, precipitation) as they affect plant growth and organic matter decomposition; similar weather- $\mathrm{CO}_{2}$ flux linkages are anticipated for fossil fuel consumption but are typically not incorporated into large-scale atmospheric simulations. High-frequency physical variations in the strength of near-surface mixing and the thickness of the planetary boundary layer also modulate the strength of the atmospheric $\mathrm{CO}_{2}$ signal by altering the volume over which a particular $\mathrm{CO}_{2}$ flux is spread. Finally, synoptic meteorological systems are responsible for vertical mixing processes and lateral advection of remotely generated $\mathrm{CO}_{2}$ anomalies over a fixed measurement site. This last process is particularly important when surface fluxes act to produce strong gradients in atmospheric $\mathrm{CO}_{2}$ that are then worked on by the atmospheric circulation.

The objective of the current study is to gain a better understanding of the processes associated with the observed synoptic variations and the relative importance of atmospheric dynamics and surface $\mathrm{CO}_{2}$ flux fields in driving the observed variability. The analysis will be carried out using a high-resolution, regional atmospheric transport model. Earlier regional studies have mainly focused on the Arctic region and have typically included monthly mean fluxes (Yuen et al., 1996; Brandefelt and Holmén, 2001; Geels et al., 2001). Recently, an hourly biospheric exchange has been included in simulations of the summertime atmospheric $\mathrm{CO}_{2}$ over western Eurasia (Chevillard et al., 2002; Kjellström et al., 2002). In the current study the flux field for the exchange of $\mathrm{CO}_{2}$ with the terrestrial biosphere is from a highresolution terrestrial biospheric model (the NCAR Land Surface Model, LSM), with horizontal resolutions of $1^{\circ} \times 1^{\circ}$ and $3^{\circ} \times$ $3^{\circ}$, and temporal resolutions of $1 \mathrm{~d}$ and 1 month. The Land Surface Model is an advanced land surface parametrization driven by meteorological reanalysis data (Bonan, 1996). The transport model has been run for the years 1991-1998 with the $\mathrm{LSM} \mathrm{CO}_{2}$ fluxes and monthly flux fields for the exchange of $\mathrm{CO}_{2}$ with the oceans and due to fossil fuel combustion. The resulting simulated atmospheric concentration fields are compared with daily means of continuous observations from four stations located in North America and Europe.

The paper is organized as follows. Section 2 gives a description of the transport model and the four monitoring sites. Section 3 demonstrates the model skill in successfully reproducing various aspects of the observations, including the strong seasonality to the synoptic variability, and in simulating many of the observed synoptic events. To illustrate the relative importance of the three different $\mathrm{CO}_{2}$ fields during specific events, we present two examples of month-long time series and the meteorological conditions for the formation of a wintertime lateral advection event. Thereafter the physical and biogeochemical sources of atmospheric $\mathrm{CO}_{2}$ variability are studied statistically by analyzing the relationship between the atmospheric signal in the model and the simulated LSM fluxes and mixing height. Finally, we present a discussion of some key issues and summarize the main conclusions.

\section{Model and site description}

\subsection{The model setup}

The Danish Eulerian Hemispherical Model (DEHM) is a threedimensional atmospheric transport model developed at the National Environmental Research Institute (Denmark) and was originally used to study long-range transport of air pollution to the Arctic (Christensen 1995, 1997). The model domain covers most of the mid and high latitudes of the Northern Hemisphere at a horizontal resolution of $150 \mathrm{~km} \times 150 \mathrm{~km}$ at $60^{\circ} \mathrm{N}$ (Fig. 1). The model has 14 layers in the vertical on terrain following $\sigma$ coordinates, with the highest resolution near the ground ( $\sim$ four layers in the lowest $1 \mathrm{~km}$ ). Recently (Geels et al., 2001), the initial version of the model has been further developed to include atmospheric $\mathrm{CO}_{2}$ by implementing fossil fuel emissions (Andres et al., 1996), $\mathrm{CO}_{2}$ exchange with the oceans based on an air-sea gas exchange parametrization (Wanninkhof, 1992) and a surface $p \mathrm{CO}_{2}$ climatology (Takahashi et al., 1999), and a flux for the terrestrial biosphere (Fung et al., 1987). Results showed that the model successfully simulated a majority of the observed seasonal and synoptic variations at marine stations in the North East Atlantic region, but underestimated the synoptic variations over the continents. As the focus now is moved from the remote marine environments to continental interiors, it is essential to update the model to include a more detailed representation of the exchange with the terrestrial biosphere.

The source functions used in the present version of the model are as follows.

(1) $\mathrm{A} 1^{\circ} \times 1^{\circ}$ emission inventory of anthropogenic $\mathrm{CO}_{2}$ for 1990 from the EDGAR V2.0 database (Olivier et al., 1996). The main difference between the EDGAR V2.0 data and the data 
by Andres et al. (1996) is the use of additional information on activity (energy production and consumption) and area-source data, which results in a more precise spatial distribution of the emissions, including major point sources. A weak seasonal variation with higher emissions during the winter months north of $30^{\circ} \mathrm{N}$ is assumed (Rotty, 1987).

(2) The monthly exchange with the oceans is the same as the previous version of the model, with the net air-sea flux $(F)$ driven by wind speed and the difference in partial pressure $\left(\Delta p \mathrm{CO}_{2}\right)$ of $\mathrm{CO}_{2}$ at the interface: $F=k K_{0} \Delta p \mathrm{CO}_{2} . k$ is the gas transfer velocity estimated from an empirical quadratic relationship with the wind speed at $10 \mathrm{~m}$ (Wanninkhof, 1992), while $K_{0}$ is the solubility of $\mathrm{CO}_{2}$.

(3) The terrestrial $\mathrm{CO}_{2}$ fluxes are produced by the NCAR LSM, a land surface process model including parametrizations of photosynthetic uptake and respiratory release of $\mathrm{CO}_{2}$ (Bonan, 1996). The biosphere is assumed to be in balance and the respiratory fluxes are scaled against the total carbon assimilation in order to obtain a local net zero flux on a yearly basis. Similar assumptions have been applied in previous studies (Fung et al., 1987; Denning et al., 1996a). The Land Surface Model is driven by meteorological data from the National Centers for Environmental Prediction (NCEP, Kalnay 1996) covering the period 1990-1998, with a horizontal resolution of approximately $1.9^{\circ} \times 1.9^{\circ}$. The NCEP precipitation is scaled to agree with observations (Bonan et al., 2002). Surface types are derived from a $0.5^{\circ} \times 0.5^{\circ}$ data set (Olson et al., 1983), and patches of plant types with different characteristics are treated separately within each grid square (same atmospheric forcing). By interpolation of the input data, LSM can be run with different horizontal resolutions, and here the various components of the biosphere-atmosphere exchange have been run at both $1^{\circ} \times 1^{\circ}$ and $3^{\circ} \times 3^{\circ}$ and are archived as daily and monthly means.

To investigate the sensitivity of the simulated concentration fields to a change in resolution in the surface fluxes, runs are performed with each of the four different spatiotemporal resolution combinations of the LSM fluxes. In the following discussions a model run named, for example, 'LSM: $1^{\circ} \times 1^{\circ}$, daily' refers to the model run with the LSM fluxes with the corresponding spatiotemporal resolution, as well as fossil fuel emissions and ocean exchange.

The DEHM is run with these three source functions using meteorological data obtained from the European Centre of Medium-Range Forecasts (ECMWF) for the period October 1990-December 1998. The global mean concentration of atmospheric $\mathrm{CO}_{2}$ for 1990 (355 ppmv) is used as initial concentrations in the model.

As DEHM is a regional model, it is necessary to prescribe the concentrations at the lateral boundaries. In this experiment, as we are focusing on short-term variability, the lateral boundaries are fixed at $355 \mathrm{ppmv}$ (same as for the initial conditions). One result of this is to counter the effect of the unbalanced fossil and ocean source components, and therefore the annual mean $\mathrm{CO}_{2}$ content within the domain is approximately constant throughout the 8-yr period (Geels et al., 2001). The four locations are far from the boundaries $(>2800 \mathrm{~km})$ and sensitivity studies show that the effect of the boundary condition is negligible on synoptic variability analyzed in the present study (Geels, 2003).

The net $\mathrm{CO}_{2}$ flux at the surface is distributed evenly up to a model estimated mixing height, determined by the model derived sensible heat flux and mechanical turbulence. This means that during the day a given surface exchange will act on a typical mixed layer of 1000-1500 m over the continents, depending on season, location, etc., while a shallower layer of a few hundred meters will form during the night (Stull, 1988). This fast vertical mixing affects the concentration in the lowest model layers, and during periods of strong mixing the surface layer $(0-175 \mathrm{~m}$ above ground) can be assumed to approximately represent the concentration in a well mixed planetary boundary layer (PBL). However, the model may have problems during very stable conditions. It is important to bear this in mind in the following sections, where concentrations of $\mathrm{CO}_{2}$ in the model surface layer are compared with near-surface observations of $\mathrm{CO}_{2}$. The simple parametrization of the mixing height has been tested and the

Fig 1. The model domain is centered at the North Pole, here the half of the domain including the four $\mathrm{CO}_{2}$ monitoring stations is shown. The two European stations are K-Puszta $\left(47^{\circ} \mathrm{N}, 20^{\circ} \mathrm{E}\right)$ in Hungary and Westerland $\left(55^{\circ} \mathrm{N}, 8^{\circ} \mathrm{E}\right)$ located on the German island Sylt in the North Sea. In North America observations from the two tall towers Park Falls $\left(46^{\circ} \mathrm{N}, 90^{\circ} \mathrm{W}\right)$ and Grifton $\left(35^{\circ} \mathrm{N}, 77^{\circ} \mathrm{W}\right)$ situated respectively in Wisconsin and North Carolina are used.

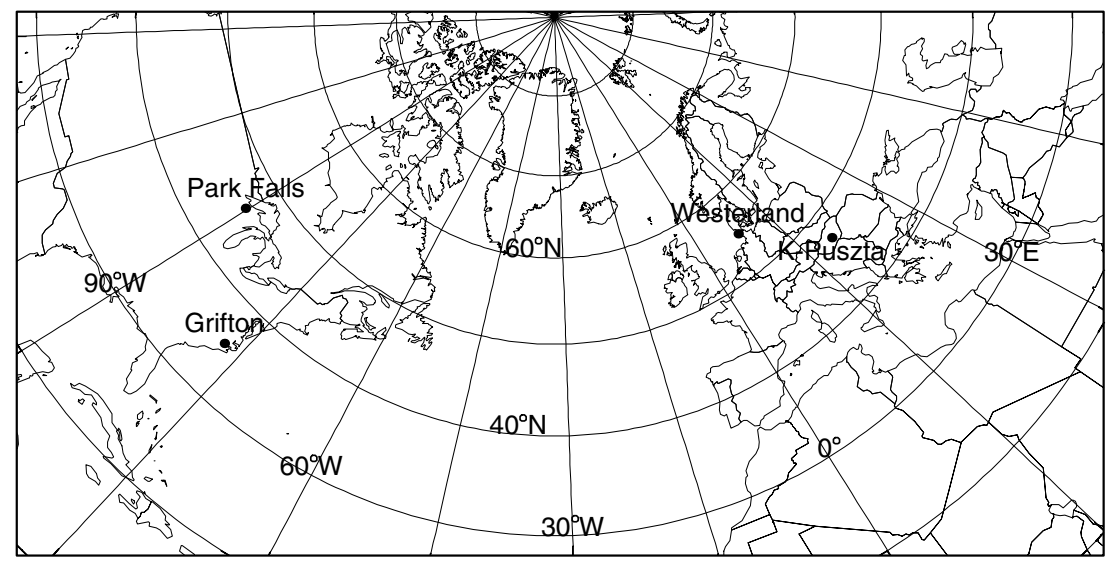


predicted heights show reasonable agreement with observations from radiosondes (Christensen, 1995). However, observations of mixing heights are highly uncertain and a thorough validation of the parametrization is complicated.

As the transport of atmospheric $\mathrm{CO}_{2}$ can be regarded as a linear problem (i.e. the concentration does not have an impact on the atmospheric transport), sources can be decomposed by mechanism and/or in space. This gives us the opportunity to investigate the relative importance of the various sources individually. We therefore run each of the fossil, ocean and terrestrial sources separately and then sum them later.

For completeness the sensitivity to the inclusion of a diurnally varying exchange with the biosphere has also been tested. Model studies (e.g. Denning et al., 1996b; Chevillard et al., 2002) have demonstrated that the co-variance between atmospheric mixing processes and surface exchange with the biosphere on both seasonal and diurnal time scales (the so-called rectifier effect) is an important process in determining the horizontal and vertical $\mathrm{CO}_{2}$ gradients in the atmosphere, especially over the continents. The ability of different transport models to reproduce the seasonal part of the rectifier has been recognized as a main explanation for the spread among budget studies (Gurney et al., 2002). In order to study the influence of the diurnal rectifier on the synoptic concentration variability, the DEHM model has been run for a full year with a diurnally varying LSM flux. The resulting daily mean values have been compared to the corresponding values from a model run with daily mean LSM fluxes. In most regions only minor differences are seen between the two model runs. At some locations over the continents, the diurnal variability leads to an increase in the concentration level close to the surface during summer, while the temporal variability is essentially the same whether a diurnally varying or a diurnally averaged exchange with the biosphere is assumed. The inclusion of the diurnal cycle is hence potentially important for budget studies, but not crucial when the synoptic scale variability is studied. Daily mean fluxes, therefore, have been applied in the current study, and the effect of the diurnal flux variability on the long-term vertical and horizontal concentration gradients will be discussed in a later study.

\subsection{The study sites}

Several stations collecting in situ measurements of $\mathrm{CO}_{2}$ at continental sites have been established around Europe in connection with a Global Atmosphere Watch (GAW) program. Based upon data availability and coverage, measurement height, etc. two stations have been chosen as adequate for this study (see Fig. 1). The station at K-Puszta (125 m a.s.1.) is located on the Hungarian Great Plain, central Europe in a clearing within a mixed forest (Haszpra, 1995, 2001). The distance to the nearest large city (>100 000 inhabitants) is approximately $20 \mathrm{~km}$. As part of a national monitoring network in Germany a coastal station has been established at Westerland $(8 \mathrm{~m}$ a.s.1.) on the island Sylt in the North Sea (Graul and Uhse, 2001). Westerland is influenced by both maritime and continental air masses, and especially during periods when the wind is off the North Sea, North Atlantic background concentrations are observed at the station (Levin et al., 1995). The air inlets for the measurements at these two stations are within $10 \mathrm{~m}$ above the ground.

In the United States, the National Oceanic and Atmospheric Administration Climate Monitoring and Diagnostics Laboratory (NOAA/CMDL) has equipped a few existing tall communications towers for continuous in situ monitoring of $\mathrm{CO}_{2}$ and other trace gases (see Bakwin et al., 1998, and references therein). The tower near Park Falls in Wisconsin is $447 \mathrm{~m}$ tall (base at $472 \mathrm{~m}$ a.s.l.), and $\mathrm{CO}_{2}$ measurements are collected at seven levels from $11 \mathrm{~m}$ up to $396 \mathrm{~m}$ above ground. The region surrounding the tower consists mainly of mixed forest, wetlands, some agriculture and a few small villages. In eastern North Carolina a few kilometers west of Grifton a $610 \mathrm{~m}$ tall (base at 9 $\mathrm{m}$ a.s.l) television and radio tower is located in a region dominated by forest, agriculture and some light industry. Continuous measurements are available at 51, 123 and $496 \mathrm{~m}$ above the ground.

An important issue in this study is that the two European stations we analyse sample at a height of only $10 \mathrm{~m}$ above the ground, while the lowest level of the model covers 0-175 m. In situ measurements collected near the ground will be affected by local conditions and low elevation continental locations will typically have a large spatial representativeness only during the early afternoon hours when the meteorological conditions are most favorable to mixing (Haszpra, 1999). Bakwin et al. (1998) have shown that measurements from $>50 \mathrm{~m}$ approximately represent a mean PBL concentration. To study the impact of this model-data mismatch, we examine the $\mathrm{CO}_{2}$ measurements from the two North American sites at both the lowest levels $(51 \mathrm{~m}$ at Grifton and $11 \mathrm{~m}$ at Park Falls) and at a height more representative of the surface layer of the model (123 m at Grifton and $122 \mathrm{~m}$ at Park Falls).

\section{Results}

\subsection{Time series}

The combination of the atmospheric transport model and the three source functions is validated by comparison with both flask and continuous $\mathrm{CO}_{2}$ observations within the model domain. As an example of the general model performance, the unfiltered results (daily means) for 1992-1993 at Ocean Station M are shown in Fig. 2. This station is located in the Norwegian Sea and is therefore not directly affected by strong anthropogenic or biospheric local sources, which makes it easier to study the seasonal signal. 


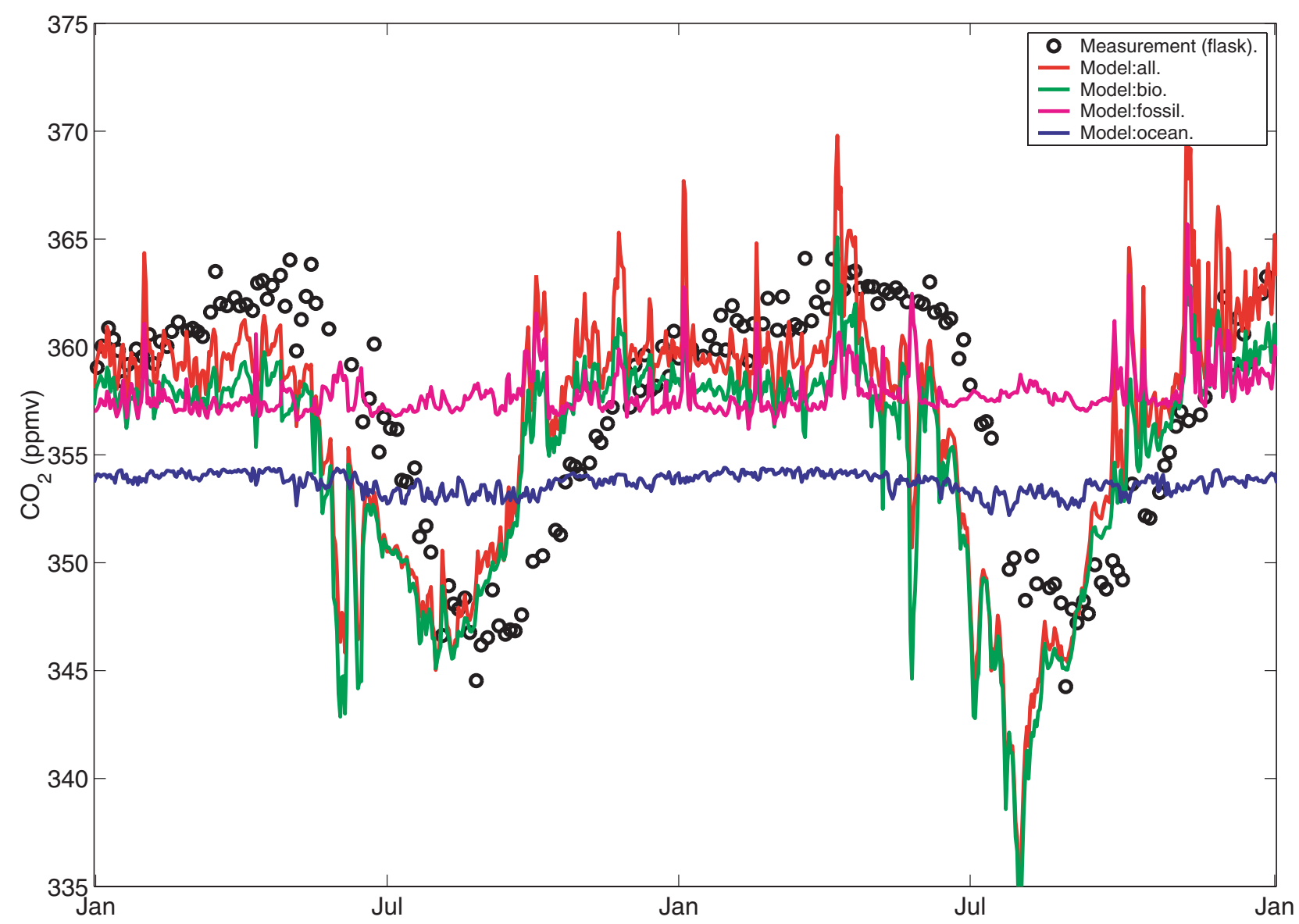

Fig 2. The observed (bi-weekly) and simulated (daily mean) concentration of atmospheric $\mathrm{CO}_{2}$ at Ocean Station $\mathrm{M}$ in the Norwegian sea $\left(66^{\circ} \mathrm{N}\right.$, $2^{\circ} \mathrm{E}$ ) for the period 1992-1993. The results of four different model runs (see legend) are shown including the three source functions separately and together. The latter is equal to the sum of the three other curves.

It is seen that the model run including the three source functions captures the amplitude of the seasonal cycle, whereas the timing of the simulated uptake and release and hence the summer minima leads the observations by approximately 1 month. This is a general tendency in the model domain, and is controlled by the seasonal cycle of the biospheric fluxes from LSM. Previously LSM has been coupled to the NCAR Community Climate Model (CCM3), and some parameters connected to the biospheric process were calibrated under the CCM 3 forcing to obtain consistency with observations (Craig et al., 1998). The same version of LSM is used in this study forced by NCEP data, which could lead to a shift in the seasonality of the fluxes (G. B. Bonan, NCAR, personal communication, 2001). Generally biospheric models have been shown to predict the amplitude of the seasonal cycle reasonably well, whereas the phase is more difficult to simulate unless constrained by satellite data (Heimann et al., 1998; Dargaville et al., 2002). In the present study, the focus is on the flux response to synoptic variations in the driving meteorology, and such a highly parametrized model would not be suitable. Figure 2 also gives an example of the relative importance of the various sources/sinks for $\mathrm{CO}_{2}$ in the model at a remote oceanic location.

In order to study the relative contribution of the various source types to the synoptic events over the continents in more detail, a pair of month-long time series will be discussed in the following. In Fig. 3 time series of daily mean observed $\mathrm{CO}_{2}$ and model simulations of the total $\mathrm{CO}_{2}$ as well as the separated components are shown for Westerland (July, 1998) and Park Falls (February, 1998), respectively. In order to ease the interpretation of these time series, the model results as well as the observations are displayed as deviations from a yearly mean and the high-pass filter (see below) has hence not been applied.

The modeled July time series at Westerland compares well against the observations and is seen to include the same overall variability and tendencies as the observed time series. The synoptic variability spans a range of more than 20 ppmv in the daily mean in both observations and model, and in the simulation it is dominated by the biospheric component. Due to the net biosphere carbon uptake over the spring and summer, the simulated biosphere $\mathrm{CO}_{2}$ concentrations over the continent are much lower 

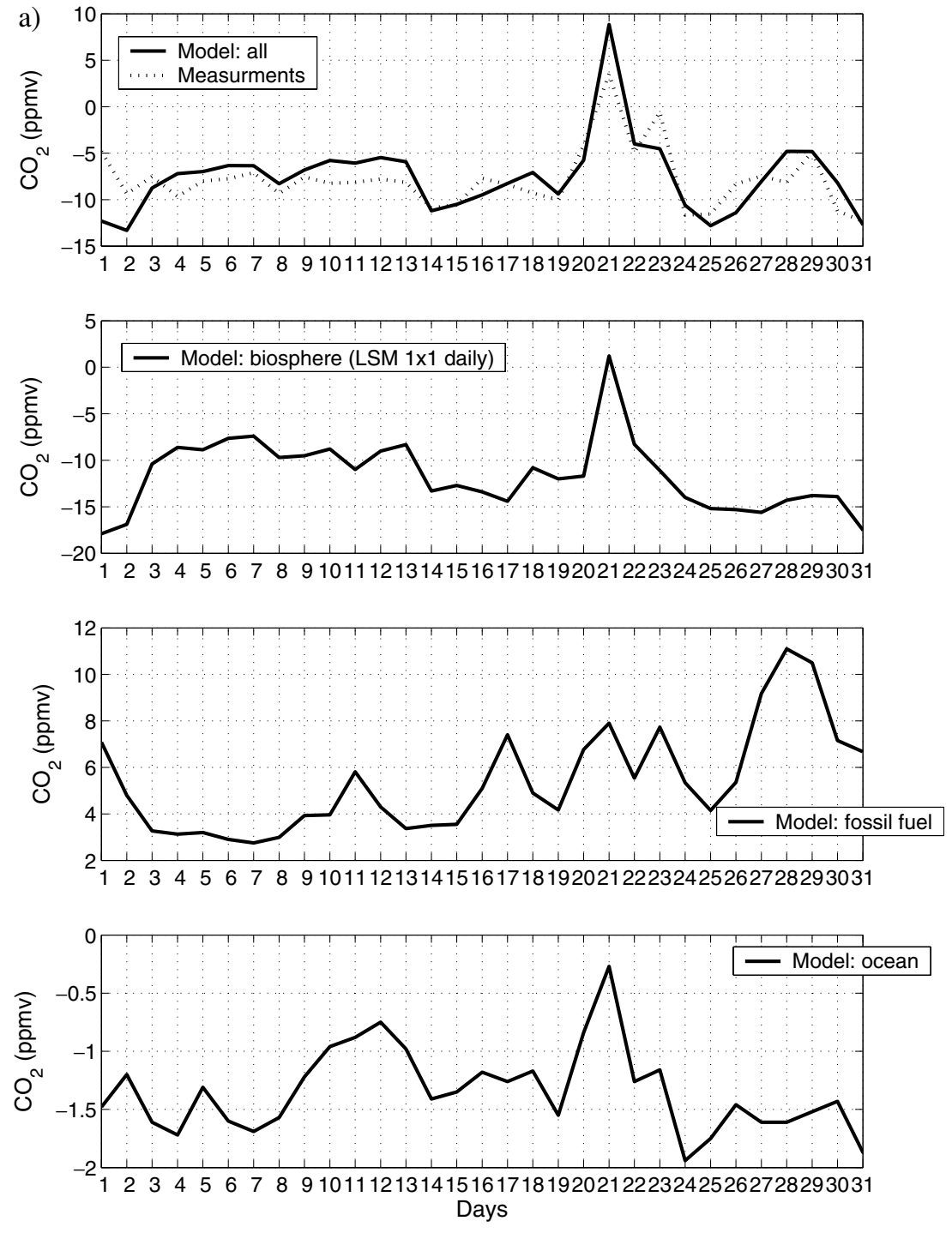

Fig 3. Time series for Westerland (a) and Park Falls (b) for July and February 1998, respectively. The flux fields included in the various model runs are given in the legends. A yearly mean concentration has been subtracted the time series. The observations from the Park Falls tower is from the lowest level. than the yearly mean concentration. At this coastal station, the summer synoptic events are typically seen as negative anomalies in the biospheric $\mathrm{CO}_{2}$ fields combined with smaller positive anomalies in the fossil fuel fields when continental air masses reach the site and vice versa when oceanic air masses dominate. Note, however, how the observed positive anomaly around the 21 st of the month is seen as a positive anomaly in the biospheric component as well as in the fossil fuel and oceanic component indicating a continental origin. Lafont et al. (2002) has shown that even during the growing season, days with a net positive flux from the biosphere can occur due to cloudy periods limiting the incoming radiation and hence photosynthesis. In this period of July the transport is mainly from Western Europe and England where a low-pressure system and associated changes in cloudiness could explain the positive anomaly seen in the biospheric component.
The variability contributed by the oceanic component during these events is seen to be more minor. The northern part of North Atlantic acts as a net sink for atmospheric $\mathrm{CO}_{2}$ in July and the $\mathrm{CO}_{2}$ content at Westerland can according to the model simulations be lowered by approximately -1.5 to -2 ppmv during episodes lasting a few days.

Figure $3 \mathrm{~b}$ displays a similar time series record but for a winter month at the Park Falls monitoring site. Again the model simulations are seen to mimic much of the observed variations during this month where three positive events mark the signal. The biospheric and fossil fuel simulations are now in phase and show the same temporal variability. The oceanic component is again small varying between approximately -0.2 to $-0.8 \mathrm{ppmv}$ at this inland location. The three events of enhanced $\mathrm{CO}_{2}$ concentrations $(\sim 10 \mathrm{ppmv})$ are linked to the passing of large-scale pressure systems, which leads to sudden changes in the wind 

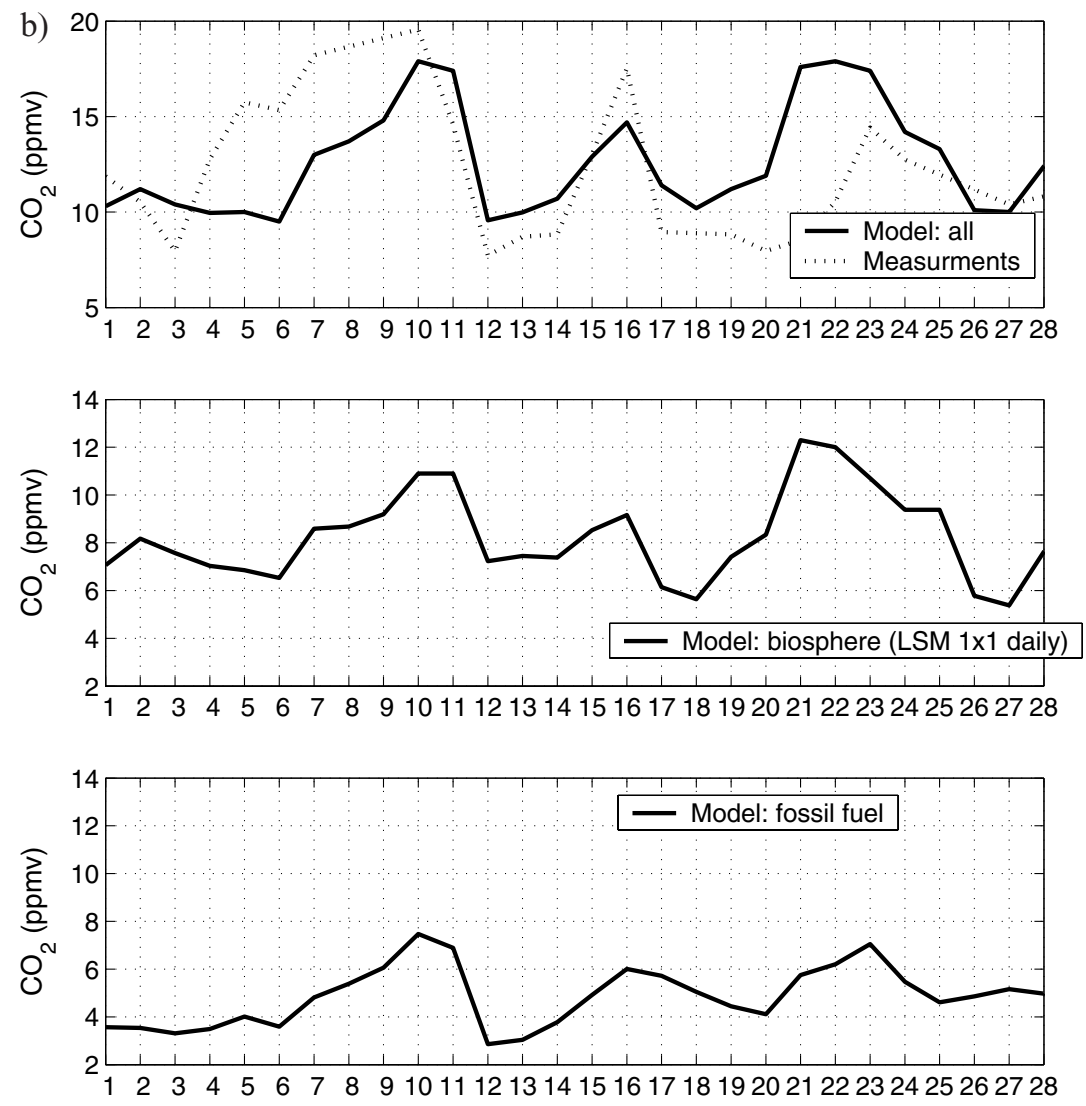

Fig 3. (cont'd)

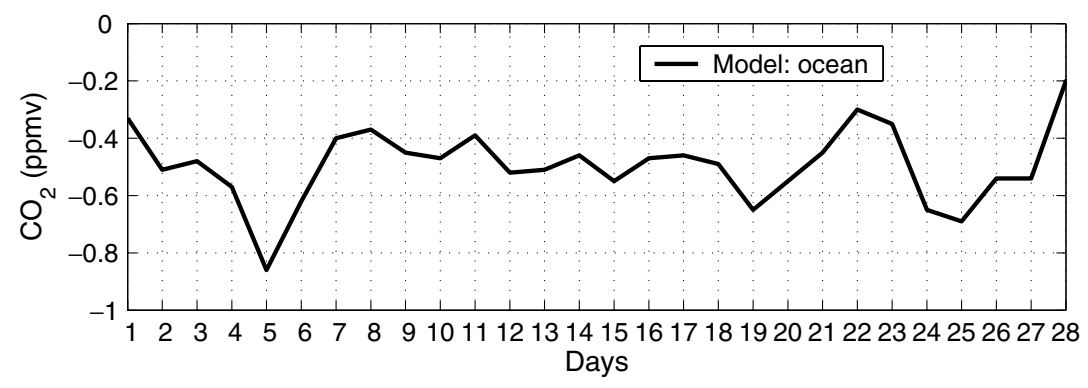

direction at Park Falls and brings air masses from different source regions over the site. In Fig. 4 the simulated surface $\mathrm{CO}_{2}$ concentration field (6-h mean) is shown together with the mean sea-level pressure for February 6 and 11, 1998. These plots indicate the overall meteorological conditions just before and within the first event at Park Falls. At the beginning of the month, a stable period with northerly winds dominates in the Park Falls region seen as a period with low $\mathrm{CO}_{2}$ values in the time series. Thereafter, the combination and movement of a high-pressure system along the east coast and a low-pressure system over the more central parts of the country leads to the advection of elevated $\mathrm{CO}_{2}$ from the east to Park Falls for a period of several days.

A typical example of a winter situation is also seen over $\mathrm{Eu}-$ rope during this specific period. A longitudinal gradient with highest emissions/fluxes in the western part of Europe exists in the fossil fuel and biosphere $\mathrm{CO}_{2}$ flux data during winter (not shown). A similar gradient is therefore at times reflected in the $\mathrm{CO}_{2}$ concentration field over Europe (Fig. 4a). In the days around February 11 the strong westerly flow related to the development and movement of a low pressure system over Scandinavia results, however, in a reversed gradient with the highest concentrations towards the east. Examples like this illustrate the complex interplay between lateral transport and the underlying flux fields for the formation and synoptic scale variability of the atmospheric $\mathrm{CO}_{2}$ field.

\subsection{Seasonality of synoptic concentration variability}

Unless otherwise stated, all the variables discussed in the rest of this paper (daily means of the simulated/observed 
a)

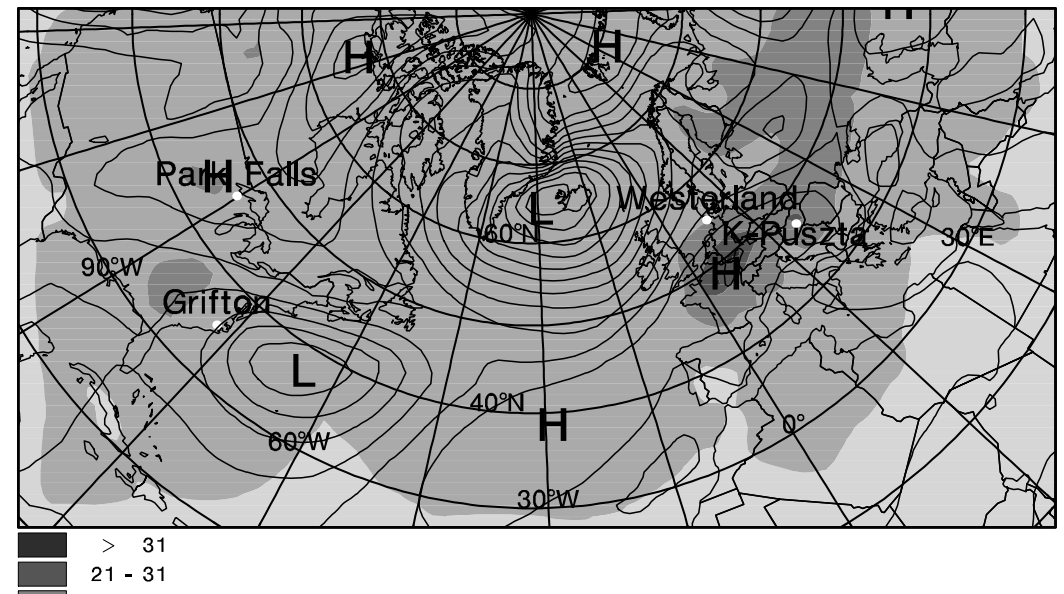

$11-21$

$1-11$

units: ppmv

b)

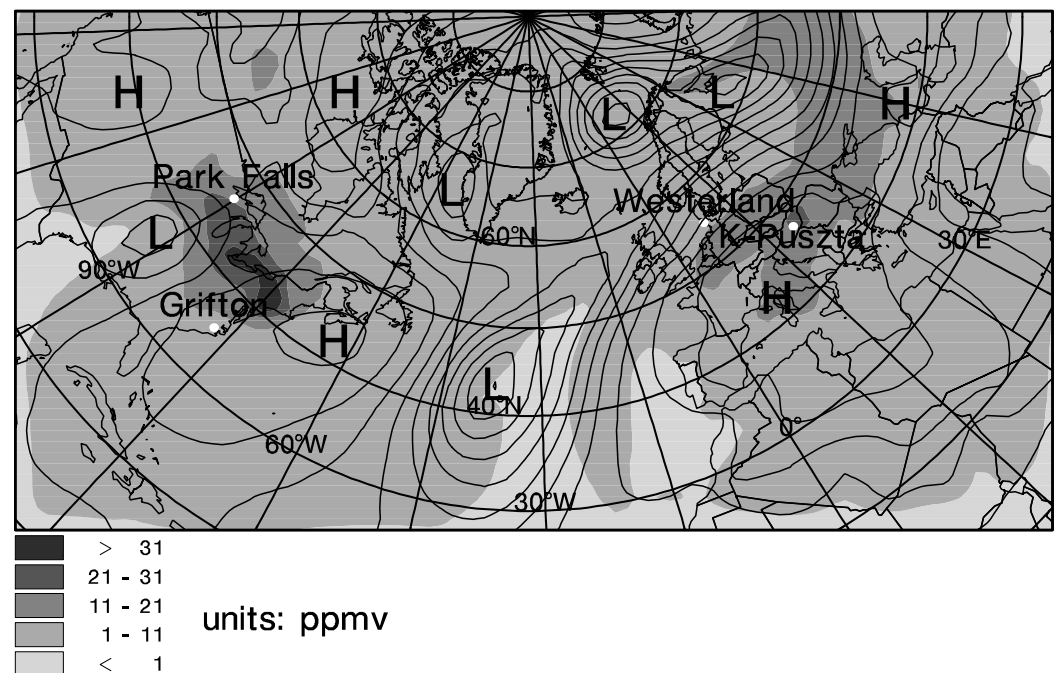

Fig 4. The 6-h mean surface concentration at 6 GMT at to dates in February 6 and 11, 1998. The contour lines indicates the mean-sea level pressure, with the $\mathrm{L}$ and $\mathrm{H}$ specifying low- and high-pressure centers, respectively.
$\mathrm{CO}_{2}$ concentrations, LSM fluxes and meteorological data) have been put through a high-pass filter in order to remove the longterm (low-frequency) variations mostly associated with the seasonal cycle. A Butterworth filter is used which retains variability on time scales shorter than 2 months (Emery and Thomson, 2001). Gaps in the measured time series have been filled by interpolation where possible. Otherwise a mean concentration has been used to obtain a continuous series for the high-pass filter.

Data coverage at the four stations varies from approximately $43 \%$ (Park Falls, continuous monitoring began in fall 1994) to $76 \%$ (K-Puszta) for the period 1991-1998. In the statistical analysis only days with observations are included. The simulated concentrations used are all from the model surface layer (0$175 \mathrm{~m}$ above ground).

A direct comparison of the calculated and observed high-pass filtered $\mathrm{CO}_{2}$ concentrations at the four stations is given in Fig. 5. The simulated concentrations in the model surface layer from an example year for two different model runs with the highest- and lowest-resolution land surface fluxes are compared with observed concentrations. Both observations and model results display considerable concentration variability on synoptic time scales. The timing of the variations is often captured, though the size of the observed anomalies is sometimes over- or underestimated. A statistical evaluation is given in the next section.

The temporal variability both in observed and simulated concentrations is clearly seen to be seasonally dependent, but with different patterns at the North American and European stations. By calculating a standard deviation (SD) of monthly binned daily concentrations, this geographic difference in the seasonality of synoptic variability is even more evident. Figure 6 shows the SD of both observed and simulated concentrations based on available data within the period 1991-1998. The observed SD at the two North American stations have a distinct maximum around summer and much lower values in spring and winter. Station K-Puszta has a much less well defined seasonal cycle, and Westerland has the reversed seasonality compared with the 

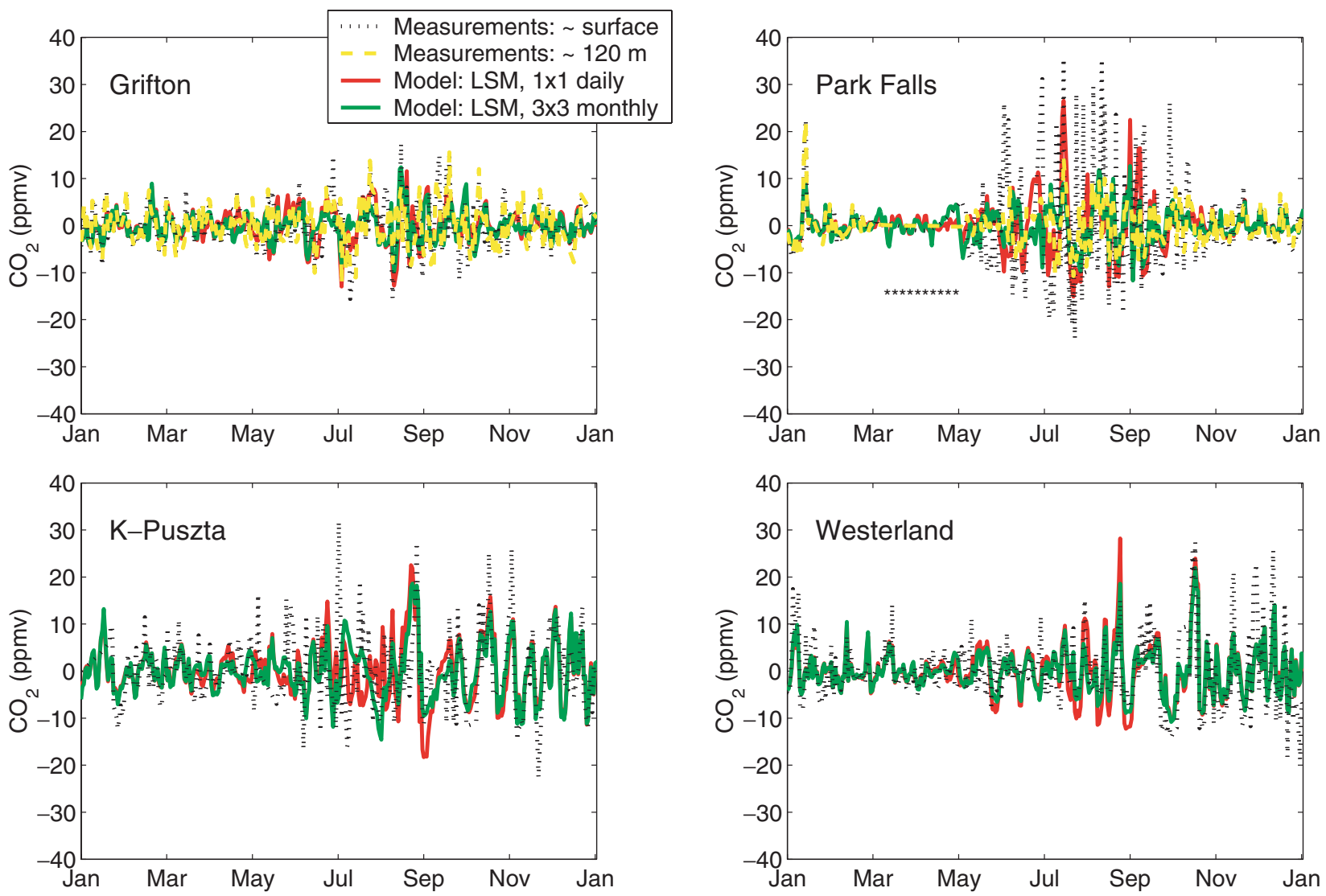

Fig 5. The daily mean concentration of atmospheric $\mathrm{CO}_{2}$ at the stations in North America (top) and Europe (bottom) during 1995. Two different model runs (with three source functions) are shown including the extreme combination of the spatiotemporal resolution of the input data from LSM: $1^{\circ} \times 1^{\circ}$, daily mean (red) and $3^{\circ} \times 3^{\circ}$, monthly mean (green). At Park Falls a longer period without measurements is marked with an asterisk.

North American stations. In general, each of the four full model runs, including the different combinations of spatiotemporal LSM fluxes, captures this seasonality at all four stations. By comparing these model runs, it is seen that higher temporal resolution of the LSM flux field results in higher variability from spring to late summer, while at each of the four sites, the SDs of the four combinations of spatial and temporal resolution simulations are nearly identical during the winter months. This is not surprising as one would expect to find the main differences in our simulations during summer when the biospheric fluxes in general are higher and therefore more sensitive to changes (and resolution) in the forcing parameters.

The two runs with the same temporal resolution but different spatial resolution are almost indistinguishable at each site, and we can conclude that in this case higher spatial resolution does not result in more detailed flux fields. This is probably due to the fact that LSM is forced with the relatively low-resolution $\left(\sim 1.9^{\circ}\right.$ $\times 1.9^{\circ}$ ) NCEP data, and as LSM includes patches of plant types within the grid squares, an increase in spatial resolution in the model runs does not necessarily result in a significant increase of the spatial variability. A general comparison of the LSM $1^{\circ} \times 1^{\circ}$ and $3^{\circ} \times 3^{\circ}$ net $\mathrm{CO}_{2}$ flux confirms that within the model domain only minor changes in the variability are caused by a shift in horizontal scales of the input data. On the other hand, the temporal resolution of the flux is seen to be important, and the daily mean LSM fluxes are necessary for the model to capture the enhanced summer variability, especially at Grifton and K-Puszta. At Park Falls the higher temporal flux resolution has the largest impact of the four stations and results in an overestimation of the variability compared with the observations at the $122 \mathrm{~m}$ level. But the model is still some way short of simulating the variability at the $11 \mathrm{~m}$ height, probably linked to the model vertical resolution. Overall the model resolution experiments demonstrate that high-frequency variation in the biospheric surface fluxes is a significant contributor to the observed synoptic surface $\mathrm{CO}_{2}$ variability in spring, summer and fall.

Based on the model run with only fossil fuel emissions (shown in Fig. 6), it can be seen that the fossil fuel contribution to the SD level is approximately $1-1.5 \mathrm{ppm}$ year round at the North American stations. The contribution to the total winter variability is therefore partitioned more or less equally between the biospheric and anthropogenic sources. This differs somewhat with findings by Bakwin et al. (1998), who by correlating observed CO and $\mathrm{CO}_{2}$ concentrations from Grifton found that anthropogenic 

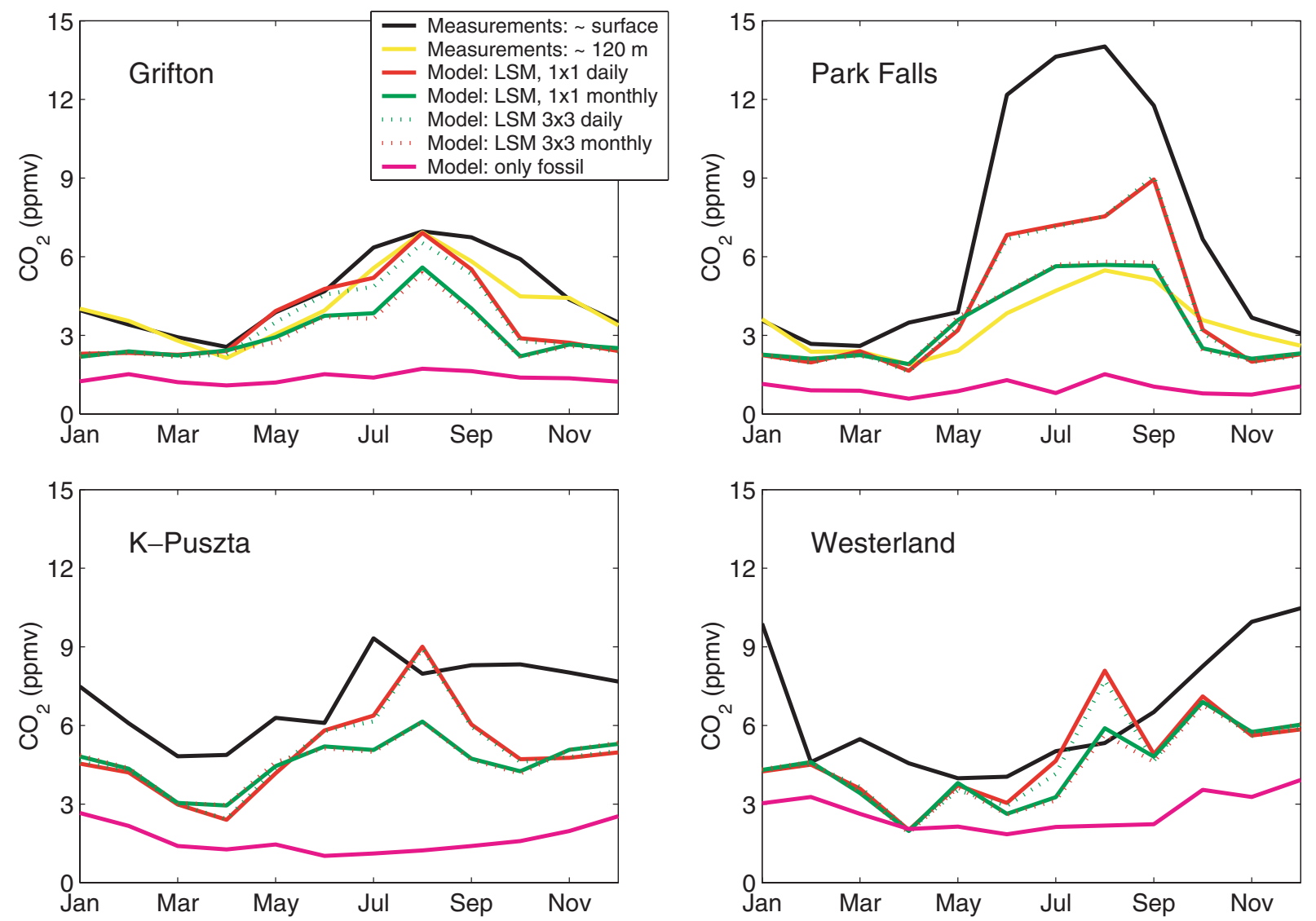

Fig 6. Standard deviation of monthly binned $\mathrm{CO}_{2}$ concentration in the years 1991 to 1998 . Only days with observations are considered and months with low coverage are not included in the calculations. At the towers measurements from two altitudes are shown. Grifton: $51 \mathrm{~m}$ (black) and $123 \mathrm{~m}$ (yellow). Park Falls: $11 \mathrm{~m}$ (black) and $122 \mathrm{~m}$ (yellow). The results of four model runs including the exchange with the biosphere, the ocean and the fossil fuel emissions are shown. The legend indicates the resolution of the applied LSM flux field. Note that the results from a model run only including fossil fuel emissions are also shown.

sources were a main contributor for winter variability, while not significant in summer. The discrepancy between our model results and the estimates by Bakwin and colleagues could point to a possible underestimation of the regional anthropogenic sources and high-frequency variability or to overestimation of the LSM fluxes during winter in the present study.

At the two sites in Europe the observed variability has a tendency towards higher values during the fall and winter months particularly at Westerland, where several large anomalies (mainly positive) are observed, see Fig. 5. This large fall and winter variability may be caused by atmospheric transport of $\mathrm{CO}_{2}$ from nonlocal anthropogenic and/or biospheric sources. As seen in both Figs. 5 and 6 the model is not fully capable of simulating the high fall and winter variability at the European sites, perhaps due to a combination of the thickness of the lowest model layer, the horizontal resolution, and the small seasonal variability and lack of high-frequency variability in the included fossil fuel emissions. Since the observations are collected near the ground, the variability will be larger than that representative of the mean PBL value (the simulated concentration). Also, the
European stations are located closer to anthropogenic sources than the stations in North America. From the fossil fuel model run the contribution to the SD by the fossil source is $\sim 1-2 \mathrm{ppm}$ in summer and $\sim 3$ ppm in winter. Levin et al. (1995) studied measurements of carbon isotopes and radon performed during the 1980s at Westerland and concluded that the seasonality of anthropogenic fossil fuel emissions was approximately three times higher than that of Rotty (1987). Still the results from the model runs including the full set of source functions illustrates that a significant part of the concentration variability is caused by the exchange with the biosphere not only in summer, but also during fall and early winter.

\subsection{Phase agreement}

To test the capability of the model to capture specific synoptic variations, model/observation correlation coefficients and linear least square regression slopes have been calculated for each station (Tables 1 and 2). Scatter plots for the four seasons at Westerland are shown as an example in Fig. 7. The seasonal 
Table 1. The correlation coefficient between daily mean observed and simulated concentrations at the four sites for the four seasons. The values are from model runs including the daily $1^{\circ} \times 1^{\circ}$ LSM fluxes or monthly $3^{\circ} \times 3^{\circ}$ LSM fluxes, with the latter in parentheses. Values marked with an asterisk are significant at the $95 \%$ level

\begin{tabular}{lllll}
\hline Site & DJF & MAM & JJA & SON \\
\hline Park Falls (122 m) & $0.62^{*}\left(0.58^{*}\right)$ & $-0.18(-0.20)$ & $0.39^{*}\left(0.25^{*}\right)$ & $0.41^{*}\left(0.53^{*}\right)$ \\
Grifton $(51 \mathrm{~m})$ & $0.47^{*}\left(0.44^{*}\right)$ & $-0.15(-0.20)$ & $0.47^{*}\left(0.41^{*}\right)$ & $0.45^{*}\left(0.33^{*}\right)$ \\
K-Puszta & $0.60^{*}\left(0.61^{*}\right)$ & $-0.02(0.07)$ & $0.11(0.12)$ & $0.38^{*}\left(0.41^{*}\right)$ \\
Westerland & $0.56^{*}\left(0.56^{*}\right)$ & $0.31^{*}\left(0.33^{*}\right)$ & $0.45^{*}\left(0.47^{*}\right)$ & $0.70^{*}\left(0.72^{*}\right)$ \\
\hline
\end{tabular}

Table 2. The slope of the linear regression between daily mean observed and simulated concentrations at the four sites and for the seasons where a significant correlation is found. The values are from model runs including the daily $1^{\circ} \times 1^{\circ}$ LSM fluxes or monthly $3^{\circ} \times 3^{\circ}$ LSM fluxes, the latter in parentheses

\begin{tabular}{|c|c|c|c|c|}
\hline Site & DJF & MAM & JJA & SON \\
\hline Park Falls $(122 \mathrm{~m})$ & $0.47(0.44)$ & & $0.58(0.27)$ & $0.53(0.50)$ \\
\hline Grifton $(51 \mathrm{~m})$ & $0.30(0.28)$ & & $0.43(0.30)$ & $0.29(0.16)$ \\
\hline K-Puszta & $0.36(0.38)$ & & & $0.23(0.23)$ \\
\hline Westerland & $0.27(0.28)$ & $0.21(0.21)$ & $0.53(0.38)$ & $0.48(0.48)$ \\
\hline
\end{tabular}

correlations and regression slopes have been compared for the two different resolutions of the LSM fluxes and are based on more than 250 daily mean concentrations in each season. The spring months March to May show poor correlations at all stations, but the high-frequency variability signal is also at a minimum in the spring. Larger correlations are found during the other three seasons. In Table 1 correlations labelled with an asterisk are significant at the $95 \%$ level according to a random phase test appropriate for time series with autocorrelation (Ebisuzaki, 1997). This method is applied when testing for significance throughout this paper. The use of high-resolution daily LSM fluxes is seen to improve the correlation during summer at the North American sites, when the biospheric contribution to variability is large. The slopes in Table 2 are all less than unity showing that the model tends to underestimate the magnitude of specific events again likely driven in part by the vertical resolution in the model.

\subsection{Factors affecting simulated $\mathrm{CO}_{2}$ concentrations}

In this section we examine the factors driving the modelled variability in the atmospheric $\mathrm{CO}_{2}$ concentrations. As shown above, the concentrations vary more in summer at Grifton and Park Fall, while the winter variability plays a larger role at K-Puszta and Westerland. In order to relate these variations to variations in the surface exchange and/or in the atmospheric mixing processes, standard deviations for various model variables are computed and presented in Fig. 8. Note that each field (of fluxes, temperature and precipitation) in Fig. 8 is calculated as an average over a footprint area of $3 \times 3$ grid boxes $(450 \mathrm{~km} \times 450 \mathrm{~km})$ surround- ing each station. The size of the area is based on the footprint size calculation of Gloor et al. (2001), which has been down scaled by a factor of approximately 5 in an attempt to account for the lower sampling heights in this study. Varying the footprint size does not significantly alter the results or our interpretation. The net $\mathrm{CO}_{2}$ fluxes from LSM show the most variability in spring and summer at all four stations, when the net exchange is large, and the variability is spatially correlated on regional scales (not shown). The variability in the estimated net fluxes at K-Puszta is considerably higher than at the other three stations, and yet the variability in the simulated concentrations is not higher. This indicates a complex relationship between the local fluxes and atmospheric concentrations. The mixing heights (as well as wind speed) and temperature variability tend to have the reversed seasonality to the $\mathrm{CO}_{2}$ fluxes and vary more in winter.

To better understand these patterns, we have calculated correlations of the net biosphere flux and mixing height anomalies against the simulated concentration anomalies (Table 3 ). We calculated the correlations at time lags of up to 2 days with the flux and transport anomalies leading the concentration anomalies and only show the maximum correlation found. As expected the net biosphere flux anomalies show a statistically significant, positive correlation with the simulated concentration anomalies at each of the four sites in summer. At the two North American sites, this correlation extends into autumn as well. During fall and winter, negative correlations are generally obtained for the mixing height anomalies and surface $\mathrm{CO}_{2}$ concentrations with a lag between 0 and 1 day. This indicates that when the PBL depth increases, positive near-surface concentration anomalies produced by fossil fuel and respiration fluxes are reduced by mixing and dilution and vice versa. Haszpra (1995) found several periods during winter when shallow stable boundary layers with low horizontal/vertical winds formed in the K-Puszta region causing an accumulation of mainly anthropogenic $\mathrm{CO}_{2}$ near the surface. Due to both the horizontal and vertical resolution of both the DEHM model and the forcing meteorology the estimated boundary layer is likely to be overestimated during such stable periods. This kind of event will hence contribute to the observed concentration variability, but will be somewhat underestimated in the model simulations. It is interesting to note that the concentration anomalies are negatively correlated with the biospheric fluxes in winter at K-Puszta and Westerland. A positive 

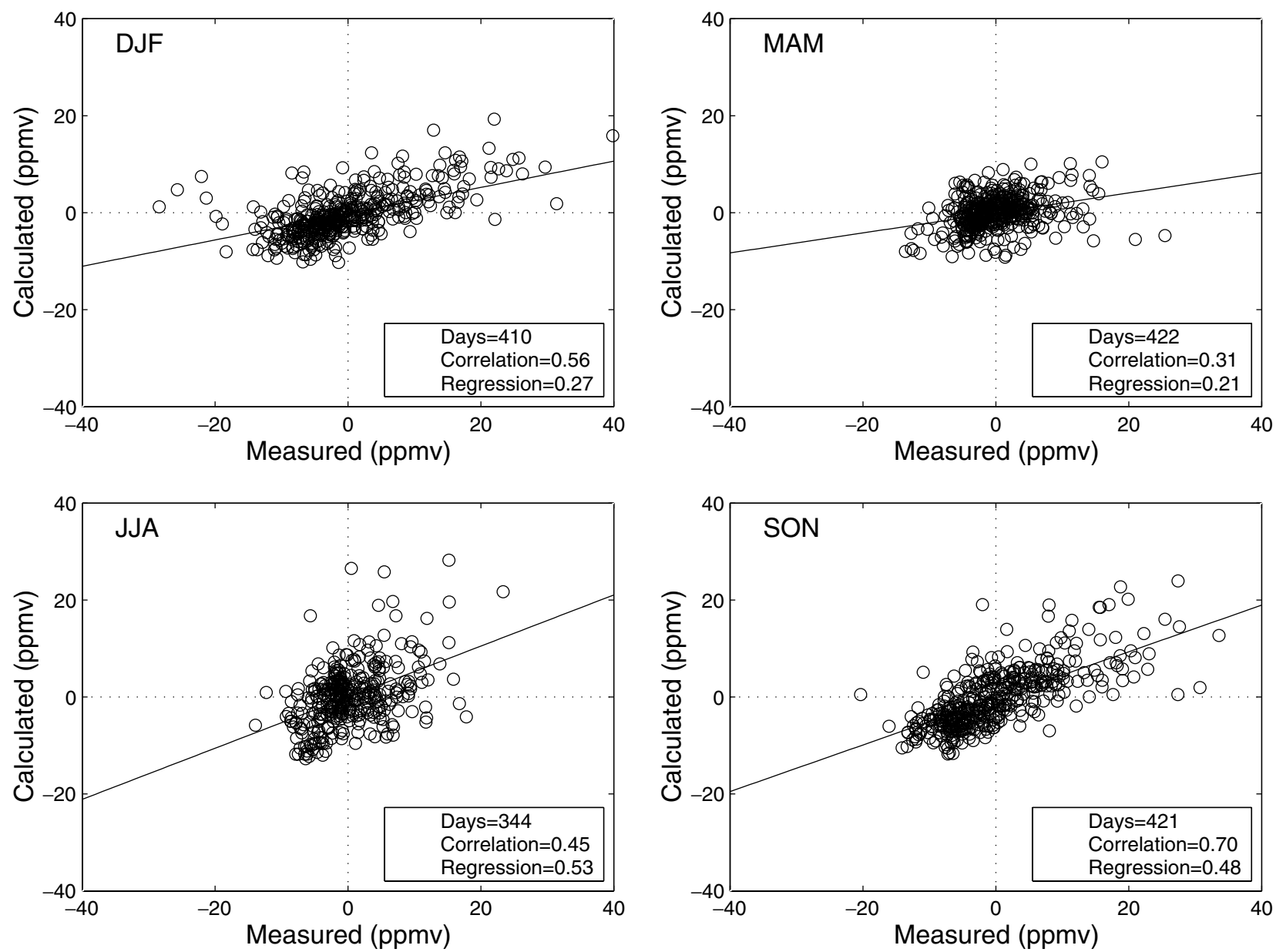

Fig 7. Scatter plots for the comparison between the concentration of $\mathrm{CO}_{2}$ as calculated by the model and monitored at Westerland. A plot for each season in the period 1991-1998 is shown. Information on number of days, correlation coefficient and slope of regression (the line) are also shown.

correlation was expected, as the biosphere generally acts as a net source for atmospheric $\mathrm{CO}_{2}$ during winter. One explanation may lay in cross-correlations between the meteorological forcing and biological fluxes. For example, under cold stable boundary layer conditions, lower temperatures would lead to reduced respiration and thus decreased atmospheric $\mathrm{CO}_{2}$ concentrations but this signal may be overwhelmed by the effect of reduced atmospheric vertical mixing. In spring (MAM), neither fluxes nor transport show significant correlations against the concentration anomalies.

\subsection{Processes affecting LSM simulated fluxes}

In this section we briefly examine the patterns of SD and the correlations ( $\mathrm{r}$ ) between the temperature and precipitation variables and the simulated $\mathrm{CO}_{2}$ fluxes. A more detailed study of these interactions will be presented in another paper focusing on the LSM model itself. From the literature it is well known that biospheric processes are influenced by a variety of environmental conditions such as solar radiation, temperature, precipitation, etc. (see e.g. VEMAP Members 1995); these are the driving variables included in LSM. Photosynthesis in the land surface model is coupled to stomatal resistance and is an integral part of the parametrizations of the surface energy fluxes. The autotrophic respiration consists of a temperature-dependent maintenance respiration and a growth respiration term, which is proportional to photosynthesis. Finally, microbial respiration $\left(R_{H}\right)$ is assumed to be a function of mainly soil temperature (by an exponential Q10 formulation), soil water content, soil carbon etc. The variability of the simulated net flux (the difference between net primary production (NPP) and $R_{H}$, Fig. 8) is controlled mainly by the large variability in NPP during late spring, summer and early fall. The variability in $R_{H}$ tends to be slightly higher than the NPP in late fall and winter when the $R_{H}$ dominates NPP, resulting in net outgassing of $\mathrm{CO}_{2}$.

From the graph of atmospheric temperature anomalies in Fig. 8, it can be seen that the temperature variability is larger at the inland stations (Park Falls and K-Puszta) compared with the coastal sites (Grifton and Westerland), where the proximity to the ocean dampens the fluctuations. The synoptic temperature 

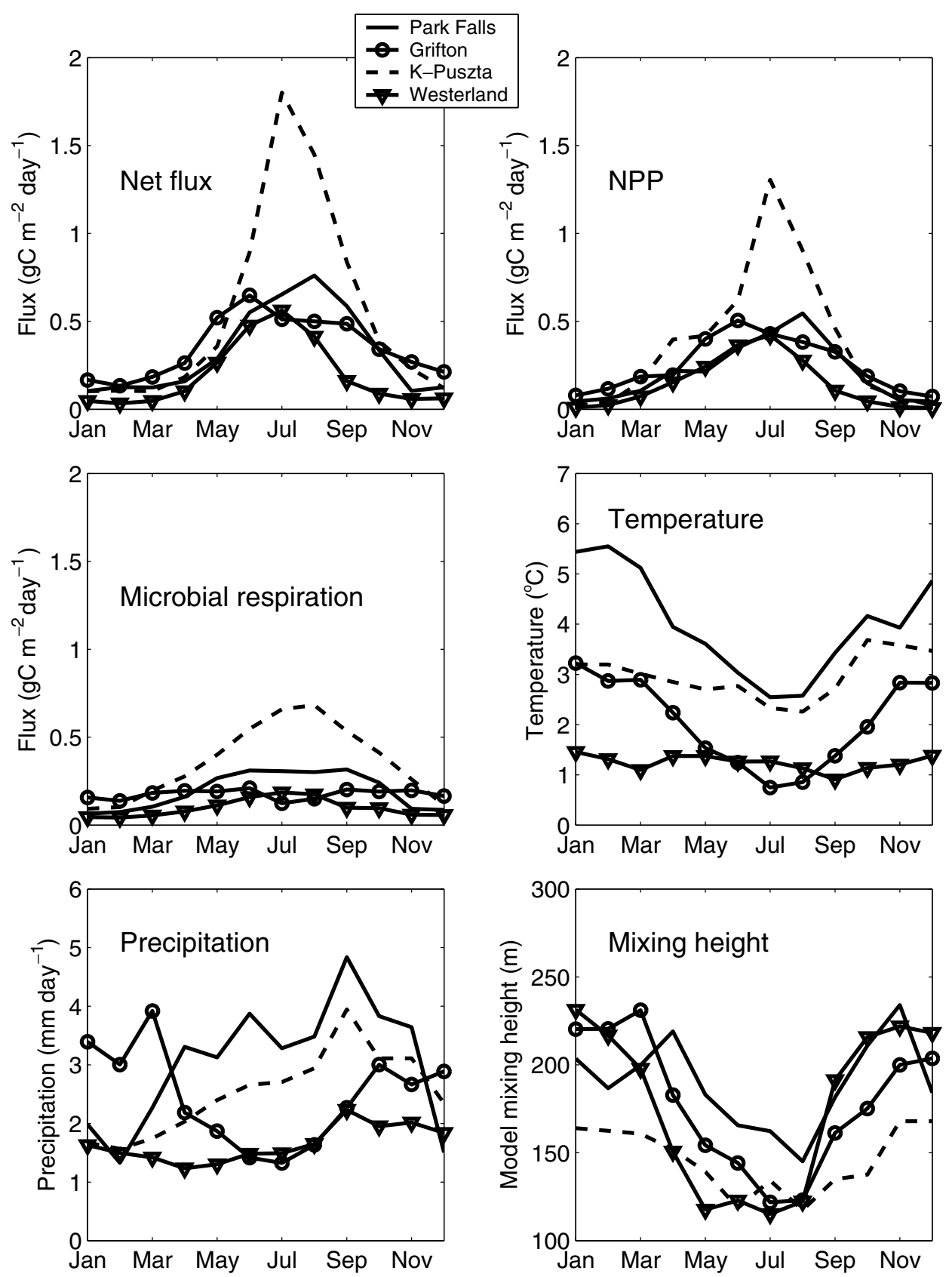

Fig 8. Mean monthly standard deviation of daily mean net flux, net primary production (NPP), microbial respiration $\left(R_{H}\right)$, surface temperature, precipitation and mixing height in the period 1991-1998. The fluxes, temperature and precipitation are means for a region $\left(\sim 2 \times 10^{5} \mathrm{~km}^{2}\right)$ around each station.

variability is largest during winter at all stations except Westerland, where the standard deviations are approximately constant throughout the year. As already mentioned, changes in temperature will have a larger impact when the biospheric fluxes are largest (i.e. summer), explaining the difference in seasonality seen in the temperature and flux variability. The synoptic variability of precipitation at the two inland stations shows a late summer maximum, while Grifton has a winter maximum. As for temperature, Westerland shows little seasonality in the variability.

Generally positive correlation coefficients higher than 0.6 are found between the net flux and temperature in summer, fall and winter. In summer we find a weak negative correlation $(r \simeq$ -0.40 to -0.46 ) between precipitation and net LSM flux at the European stations and Grifton, with precipitation leading by 1$2 \mathrm{~d}$. Low correlations between spring temperatures/precipitation 
Table 3. The highest lagged ( $0 \pm 2$ days) correlations between daily mean simulated concentration $(\Delta C)$ and estimated mixing height $(\Delta H)$ and net LSM flux $(\Delta F)$ at the four sites for the four seasons. The concentration is from a model run including the daily $1^{\circ} \times 1^{\circ} \mathrm{LSM}$ fluxes as well as fossil fuel emissions and the exchange with the ocean. Values marked with an asterisk are significant at the $95 \%$ level

\begin{tabular}{|c|c|c|c|c|}
\hline \multicolumn{5}{|l|}{$\Delta C$} \\
\hline & DJF & MAM & JJA & SON \\
\hline \multicolumn{5}{|c|}{ Park Falls } \\
\hline$\Delta H$ & $-0.50^{*}$ & -0.15 & 0.16 & $-0.26^{*}$ \\
\hline$\Delta F$ & $0.30 *$ & -0.13 & $0.50 *$ & $0.73 *$ \\
\hline \multicolumn{5}{|c|}{ K-Puszta } \\
\hline$\Delta H$ & $-0.62 *$ & 0.15 & 0.18 & $-0.45^{*}$ \\
\hline$\Delta F$ & $-0.29^{*}$ & 0.11 & $0.60 *$ & 0.32 \\
\hline \multicolumn{5}{|l|}{ Grifton } \\
\hline$\Delta H$ & $-0.30^{*}$ & 0.25 & -0.11 & $-0.31^{*}$ \\
\hline$\Delta F$ & -0.16 & 0.22 & $0.46^{*}$ & $0.42 *$ \\
\hline \multicolumn{5}{|c|}{ Westerland } \\
\hline$\Delta H$ & $-0.45^{*}$ & 0.01 & -0.23 & $-0.45^{*}$ \\
\hline$\Delta F$ & $-0.35^{*}$ & 0.12 & $0.43 *$ & 0.30 \\
\hline
\end{tabular}

and net exchange is seen at all four locations. As this is a period of rapid physiological and phenological developments, the main environmental drivers provide weaker forcing than in the other seasons (Baldocchi et al., 2001). Focusing on the two separated components of the LSM flux, a strong positive correlation between temperature and respiration $(r>0.82)$ is found for all seasons as expected, while the NPP is less controlled by temperature variations depending on location and season. For precipitation, correlations range from 0.39 to 0.49 for summer NPP at all stations except Park Falls, and at the European sites a significant negative correlation of $r \simeq-0.40$ is estimated between soil respiration and precipitation in summertime.

\section{Summary and discussion}

A regional atmospheric transport model driven by a land surface biospheric $\mathrm{CO}_{2}$ model captures a significant fraction of the synoptic ( $\sim$ days) variability of atmospheric $\mathrm{CO}_{2}$ at four continuous monitoring stations over continental regions in Europe and North America. The model results are sensitive to the temporal resolution of the biospheric fluxes, especially for the stations in North America, where the simulations including daily biospheric fluxes show enhanced synoptic variability closer to that observed than in a simulation using monthly fluxes. This result highlights the importance of local and regional factors, leading to elevated variability at continental sites. Furthermore, it demonstrates that future modelling studies wishing to make use of the continuous $\mathrm{CO}_{2}$ data from the continental interiors must use fluxes varying on at least the daily time scale. The spatial resolution of the fluxes had less of an impact, but we note that due to the limitations of the input fields, the higher resolution flux field from LSM does not contain significant spatial variability on scales of less than about $3^{\circ} \times 3^{\circ}$. More biosphere model developments are required to obtain flux estimates at this resolution.

At the European sites, the observed surface atmospheric $\mathrm{CO}_{2}$ variability is stronger in general throughout fall and winter, most likely due to the proximity to strong anthropogenic source areas and typically shallower PBL depths during the winter. The simulations underpredict this feature, perhaps due to the relatively coarse spatial model resolution and the assumed weak seasonal dependence and lack of high-frequency variability of the fossil source. As many monitoring sites are located on short $(\sim 10 \mathrm{~m})$ towers, enhanced near-surface model resolution will be required to capture the sometimes steep vertical gradients near the surface. Vertical exchange across the top of the PBL with the free troposphere is another potential problem, and one that none of the current model vertical mixing schemes does particularly well (e.g. Ayotte et al., 1996). Further efforts will also probably be needed to implement parametrizations for higher resolution spatial and temporal variability in the anthropogenic as well as the correlations with meteorology.

Standard deviations and correlations between environmental parameters have been estimated in order to study the mechanisms that drive the concentration variability in the model. In summer high, statistically significant positive correlations are found between daily mean net biospheric fluxes and simulated $\mathrm{CO}_{2}$ concentrations. Whereas in the fall and winter, the synoptic $\mathrm{CO}_{2}$ variability is negatively correlated with mixing height (and also wind speed). Owing to the formulations of the exchange processes in the LSM model, fluctuations in surface air temperatures are the main drivers for variations in the simulated net biospheric fluxes in all seasons except spring. By studying the NPP and $R_{H}$ components of this simulated flux on a regional scale, we see that NPP is highly variable during summer while soil release plays an important role in fall and winter both in North America and Europe. Studying time series of the $\mathrm{CO}_{2}$ concentration along with the evolving meteorological conditions reveals the importance of the interplay between the surface exchange and the synoptic changes in the transport processes. From a few examples is it seen that while local vertical processes (e.g. surface fluxes, vertical mixing) are important, lateral transport of remotely generated $\mathrm{CO}_{2}$ anomalies also contributes significantly to synoptic $\mathrm{CO}_{2}$. Both parts should be properly resolved in future model studies.

The simulated variability of the mixing height is probably somewhat underestimated as the DEHM model only includes four vertical layers in the lowest $1 \mathrm{~km}$. This has previously been dictated by the resolution of the ECMWF data, but a new highresolution version of DEHM is currently under development at the National Environmental Research Institute, Denmark, using the MM5 model (Grell et al., 1995), developed at NCAR and Penn State University, as the meteorological driver. Future studies will examine whether higher horizontal and vertical resolution improve the capability of the transport models to simulate synoptic variability of atmospheric $\mathrm{CO}_{2}$, and new parametrizations of the 
planetary boundary layer dynamics will also be tested. The increased vertical resolution is vital to be able to utilize stations that sample close to the ground, such as the two European stations used in this study.

As mentioned earlier, we have only focused our attention here on the daily variability, and not the sub-daily variations. The diurnal cycle impact on the daily variability is not significant, but it does have profound effects on the horizontal and vertical profiles averaged over longer time scales.

In summary, the seasonality and magnitude as well as the mechanisms driving the synoptic concentration variability at continental continuous monitoring stations vary significantly among sites and are not easily generalizable. The synoptic variability is an integral part of continental $\mathrm{CO}_{2}$, aliasing into any type of long-term average; attempts to develop higher-density sampling networks and to quantify regional $\mathrm{CO}_{2}$ source and sinks patterns will fail unless adequate treatment of the underlying biological and physical mechanisms driving the synoptic signal are properly accounted for. This study is a step towards a deeper understanding of the mechanisms driving the observed synoptic scale variability at continental sites, but additional work is required in order to fully understand the involved mechanisms and processes.

\section{Acknowledgments}

We thank R. Graul and K. Uhse, Umwelbundesamt (Germany) and L. Haszpra, Hungarian Meteorological Service (Hungary) for making the continuous $\mathrm{CO}_{2}$ data from Westerland and $\mathrm{K}$ Puszta available. Likewise we thank NOAA CMDL (US) for providing the data from Park Falls and Grifton. We are grateful to Sam Levis (NCAR) for introducing us to LSM. Critical comments from the reviewers helped to improve this manuscript. Part of this work was done, while Camilla Geels visited NCAR for a 5-month period. The National Center for Atmospheric Research is sponsored by the US National Science foundation. RD and SCD acknowledge support from the NCAR Director's Opportunity Fund. Part of the funding for this work came from the Danish Natural Science Research Council (SNF), Denmark. This is Woods Hole Oceanographic Institution Contribution No 10948.

\section{References}

Andres, R. J., Marland, G., Fung, I. and Matthews, E. 1996. A $1^{\circ} \times 1^{\circ}$ distribution of carbon dioxide emissions from fossil fuel consumption and cement manufacture, 1950-1990. Global Biogeochem. Cy. 10, 419-429.

Ayotte, K. W., Sullivan, P. P., Andren, A., Doney, S. C., Holtslag, A. A. M., Large, W. G., McWilliams, J. C., Moeng, C.-H., Otte, M. J., Tribbia, J. J. and Wyngaard, J. C. 1996. An evaluation of neutral and convective planetary boundary-layer parameterizations relative to large eddy simulations. Bound-Layer Meteorol. 79, 131175 .
Bakwin, P. S., Tans, P. P., Hurst, D. F. and Zhao, C. 1998. Measurments of carbon dioxide on very tall towers: results of the NOAA/CMDL program. Tellus 50B, 401-415.

Baldocchi, D., Falge, E. and Wilson, K. 2001. A spectral analysis of biosphere-atmosphere trace gas flux and meterological variables across hour to multi-year time scales. Agr. Forest Meteorol. 107, 1-27.

Bonan, G. B. 1996. A Land surface model (LSM version 1.0) for ecological, hydrological and atmospheric studies. Technical description and user's guide. NCAR Technical Note. National Center for Atmospheric Research, Boulder, CO. NCAR/TN-417+STR.

Bonan, G. B., Levis, S., Kergoat, L. and Oleson, K. W. 2002. Landscapes as patches of plant functional types: An integrating concept for climate and ecosystem models. Global Biogeochem. Cy. 16 (2), 1021, doi:10.1029/2000GB001360.

Bousquet, P., Paylin, P., Ciais, P., Le Quèrè, C., Friedlingstein, P. and Tans, P. 2000. Regional changes in carbon dioxide fluxes over land and oceans since 1980. Science, 290, 1342-1346.

Brandefelt, J. and Holmén, K. 2001. Anthropogenic and biogenic winter sources of Artic $\mathrm{CO}_{2}-$ a model study. Tellus 53B, 10-21.

Chevillard, A., Karstens, U., Ciais, P., Lafont, S. and Heimann, M. 2002. Simulation of atmospheric $\mathrm{CO}_{2}$ over Europe and Western Siberia using the regional scale model REMO. Tellus 54B, 872-894.

Christensen, J. H. 1995. Transport of Air pollution in the Troposphere to the Arctic, $\mathrm{PhD}$ thesis. National Environmental Research Institute, Denmark.

Christensen, J. H. 1997. The Danish Eulerian hemispheric model-a three-dimensional air pollution model used for the arctic. Atmos. Environ. 31, 4169-4191.

Craig, S. G., Holmén, K. J., Bonan, G. B. and Rasch, P. J. 1998. Atmospheric $\mathrm{CO}_{2}$ simulated by the National Center for Atmospheric Research Community Climate Model 1. Mean fields and seasonal cycles. J. Geophys. Res. 103, 13 213-13 235.

Dargaville, R. J., Law, R. M. and Pribac, F. 2000. Implications of interannual variability in atmospheric circulation on modeled $\mathrm{CO}_{2}$ concentrations and source estimates. Global Biogeochem. Cy. 14, 931-943.

Dargaville, R. J., Heimann, M., McGuire, A. D., Prentice, I. C., Kicklighter, D. W., Joos, F., Clein, J. S., Esser, G., Foley, J., Kaplan, J., Meier, R. A., Melillo, J. M., Moore, B., Ramankutty, N., Reichenau, T., Schloss, A., Sitch, S., Tian, H., Williams, L. J. and Wittenberg, U. 2002. Evaluation of terrestrial carbon cycle model through simulations of the seasonal cycle of $\mathrm{CO}_{2}$ : results from transient simulations consisting of increasing $\mathrm{CO}_{2}$, climate and land-use effects. Global Biogeochem. Cy. 16 (4), 1092, doi:10.1029/2001GB001426.

Denning, A. S., Collatz, G. J., Zhang, C., Randall, D. A., Berry, J. A., Sellers, P. J., Colello, G. D. and Dazlich, D. A. 1996a. Simulations of terrestrial carbon metabolism and atmospheric $\mathrm{CO}_{2}$ in a general circulation model, Part 1: Surface carbon fluxes. Tellus 48B, 521542 .

Denning, A. S., Randall, D. A., Collatz, G. J. and Sellers, P. J. 1996 b. Simulations of terrestrial carbon metabolism and atmospheric $\mathrm{CO}_{2}$ in a general circulation model, Part 2: Simulated $\mathrm{CO}_{2}$ concentrations. Tellus 48B, 543-567.

Eibisuzaki, W. 1997. A method to estimate the statistical signifance of a correlation when the data are serially correlated. J. Climate 10, 21472153.

Emery, J. and Thomson, R. E. 2001. Data analysis methods in physical oceanography. Elsevier. 
Erickson, D. J., III, Rasch, P. J., Tans, P. P., Friedlingstein, P., Ciais, P., Maier-Reimer, E., Six, K., Fischer, C. A. and Walters, S. 1996. The seasonal cycle of atmospheric $\mathrm{CO}_{2}$ : A study based on the NCAR Community Climate Model (CCM2). J. Geophys. Res. 101, 15 079-15 097.

Fung, I., Tucker, C. J. and Prentice, K. C. 1987. Application of AVHRR vegetation index to study atmospheric-biosphere exchange of $\mathrm{CO}_{2}$. J. Geophys. Res. 92, 2999-3015.

Geels, C. 2003. Simulating the Current $\mathrm{CO}_{2}$ Content of the Atmosphere: Including Surface Fluxes and Transport across the Northern Hemisphere. PhD thesis, National Environmental Research Institute, Denmark.

Geels, C., Christensen, J. H., Hansen, A. W., Kiilsholm, S., Larsen, N. W., Larsen, S. E., Pedersen, T. and Sørensen, L. L. 2001. Modelling concentrations and fluxes of atmospheric $\mathrm{CO}_{2}$ in the North East Atlantic region. Phys. Chem. Earth Part B, 26, 763-768.

Gloor, M., Fung, S. M. and Sarmiento J. 2000. Optimal sampling of the atmosphere for purpose of inverse modeling: a model study. Global Biogeochem. Cy. 14, 407-428.

Gloor, M., Bakwin, P., Hurst, D., Lock, L. and Draxler, R. 2001. What is the concentration footprint of a tall tower?. J. Geophys. Res. 106, $17831-17841$.

Graul, R. and Uhse, K. 2001. $\mathrm{CO}_{2}$ data from Westerland. Germany, WMO WDCGG CD-Rom Nr. 7.

Grell, G. A., Dudhia, J. and Stauffer, D. R. 1995. A Description of the Fifth-Generation Penn State/NCAR Mesoscale Model (MM5). NCAR/TN-398+STR. NCAR Technical Note. Mesoscale and Microscale Meteorology Division. National Center for Atmospheric Research. Boulder, CO, 122.

Gurney, K. R., Law, R. M., Denning, A. S., Rayner, P. J., Baker, D., Bousquet, P., Bruhwiler, P., Chen, Y.-H., Ciais, P., Fan, S., Fung, I. Y., Gloor, M., Heimann, M., Higuchi, K., John, J., Maki, T., Maksyutov, S., Masari, K., Peylin, P., Prather, M., Pak, B. C., Randerson, J., Sarmiento, J., Taguchi, S., Takahashi, T. and Yuen, C.-W. 2002. Towards robust regional estimates of $\mathrm{CO}_{2}$ sources and sinks using atmospheric transport models. Nature 415, 626-630.

Haszpra, L. 1995. Carbon dioxide concentration measurements at a rual site in Hungary. Tellus 47B, 17-22.

Haszpra, L. 1999. On the representativeness of carbon dioxide measurements, J. Geophys. Res. 104, 26 953-26960.

Haszpra, L. 2001. $\mathrm{CO}_{2}$ data from K-Puszta. Hungary, WMO WDCGG CD-Rom Nr. 7.

Heimann, M., Esser, G., Haxeltine, A., Kaduk, J., Kicklighter, D. W., Knorr, W., Kohlmaier, G. H., McGuire, A. D., Melillo, J., Moore, B., III, Otto, R. D., Prentice, I. C., Sauf, W., Schloss, A., Sitch, S., Wittenberg, U. and Würth, G. 1998. Evaluation of terrestrial carbon cycle models through simulations of the seasonal cycle of atmospheric $\mathrm{CO}_{2}$ : first results of a model intercomparison study. Global Biogeochem. Cy. 12, 1-24.

Kalnay, E. 1996. The NMC/NCAR 40-year reanalysis project. Bull. Amer. Meteor. Soc., 77, 437-471.
Kjellström, E., Holmén, K., Eneroth, K., and Engardt, M. 2002. Summertime Siberian $\mathrm{CO}_{2}$ simulations with the regional transport model MATCH: a feasibility study of carbon uptake calculations from EUROSIB data. Tellus 54B, 834-849.

Lafont, S., Kergoat, L., Dedieu, G., Chevillard, A., Karstens, U. and Kolle, O. 2002. Spatial and temporal variability of land $\mathrm{CO}_{2}$ fluxes estimated with remote sensing and analysis data over western Eurasia, Tellus, 54B, 820-833.

Law, R. M., Rayner, P. J., Denning, A. S., Erickson, D., Fung, I. Y., Heimann, M., Piper, S. C., Ramonet, M., Taguchi, S., Taylor, J. A., Trudinger, C. M. and Watterson, I. G. 1996. Variations in modeled atmospheric transport of carbon dioxide and the consequences for $\mathrm{CO}_{2}$ inversions. Global Biogeochem. Cy. 10, 783-796.

Law, R. M., Rayner, P. J., Steele, L. P. and Enting, I. G. 2002. Using high temporal frequency data for $\mathrm{CO}_{2}$ inversions. Global Biogeochem. $C y$. 16 (4), 1053, doi:10.1029/2001GB001593.

Levin, I., Graul, R. and Trivett, N. B. A. 1995. Long-term observations of atmospheric $\mathrm{CO}_{2}$ and carbon isotopes at continental sites in Germany. Tellus 47B, 23-34.

Olivier, J. G. J., Bouwman, A. F., van der Maas, C. W. M., Berdowski, J. M., Veldt, C., Bloos, J. P. J., Visschedijk, A. J. H., Zandveld, P. J. and Haverlag, J. L. 1996. Description of EDGAR Version 2.0: A set of global emission inventories of greenhouse gases and ozone-depleting substances for all anthropogenic and most natural sources on a per country basis and on $1^{\circ} \times 1^{\circ}$ grid, National Institute of Public Health and the Environment (RVIM) report $n r .771060$ 002/TNO-MEP report nr R96/119.

Olson, J. S, Watts, J. A. and Allison, L. J. 1983. Carbon in live vegetation of major world ecosystems, Rep. ORNL-5862, Oak Ridge Natl. Lab., Oak Ridge, TN.

Rotty, R. M. 1987. Estimates of seasonal variation in fossil $\mathrm{CO}_{2}$ emissions. Tellus 39B, 184-202.

Stull, R. B. 1988. An Introduction to Boundary Layer Meterology. Kluwer, Dordrecht.

Takahashi, T., Wanninkhof, R. H., Feely, R. A., Weiss, R. F., Chipman, D. W., Bates, N., Olafsson, J., Sabine, C. and Sutherland, S. C. 1999. Net sea-air $\mathrm{CO}_{2}$ flux over the global oceans: an improved estimate based on the sea-air $\mathrm{CO}_{2}$ difference. In: Proc. 2nd Int. Symp., $\mathrm{CO}_{2}$ in the Oceans. (ed.Y. Nojiri). Center for Global Environmental Research, National Institute for Environmental Studies, Tsukuba, 914.

VEMAP Members. 1995. Vegetation/ecosystems modeling and analysis project: Comparing biogeography and biogeochemistry models in a continental-scale study of terrestrial ecosystem responses to climate change and $\mathrm{CO}_{2}$ doubling. Global Biogeochem. Cy. 9, 407437.

Wanninkhof, R. 1992. Relationship between wind speed and gas exchange over the ocean. J. Geophys. Res. 97, 7373-7382.

Yuen, C. W., Higuchi, K., Trivett, N. B. A. and Cho, H.-R. 1996. A simulation of a large positive $\mathrm{CO}_{2}$ anomaly over Canadian Arctic Archipelago. J. Meteor. Soc. Japan 74, 781-795. 